\title{
PENGARUH SISTEM REKRUTMEN DAN PERILAKU ORGANISASI TERHADAP KINERJA ORGANISASI PADA PALANG MERAH INDONESIA (PMI) SIGLI KABUPATEN PIDIE
}

\author{
Syamsul Akmal ${ }^{(1)}$, Siska Hariyanti ${ }^{(2)}$ \\ ${ }^{1,2}$ Fakultas Ekonomi Universitas Jabal Ghafur \\ syamsul_akmal24@yahoo.com ${ }^{(1)}$ attanaofficial@gmail.com ${ }^{(2)}$
}

\begin{abstract}
ABSTRAK
Penelitian ini bertujuan untuk mengetahui Pengaruh Sistem Rekrutmen dan Perilaku Organisasi Terhadap Kinerja Organisasi pada Palang Merah Indonesia (PMI) Sigli Kabupaten Pidie. Variabel independen yaitu Sistem Rekrutmen $\left(\mathrm{X}_{1}\right)$, Perilaku Organisasi $\left(\mathrm{X}_{2}\right)$ dan Kinerja Organisasi (Y) sebagai variabel dependennya. Populasi dalam penelitian ini adalah anggota Palang Merah Indonesia (PMI) Sigli Kabupaten Pidie. Sampel diambil sebanyak 32 orang sampel dengan menggunakan rumus slovin. Data dikumpulkan dengan menggunakan metode survey melalui kuesioner yang diisi oleh responden. Kemudian data yang diperoleh dianalisis dengan menggunakan analisis regresi berganda. Analisis ini meliputi Uji Validitas, Uji Reliabilitas, Analisis Regresi berganda Uji Asumsi Klasik, Uji Hipotesis melalui Uji F dan Uji t, serta analisis Koefisien Determinasi $\left(\mathrm{R}^{2}\right)$. Dari hasil analisis dapat disimpulkan bahwa dari keempat variabel yang diteliti, ternyata variabel Sistem Rekrutmen $\left(\mathrm{X}_{1}\right)$ mempunyai pengaruh yang paling dominan sebesar $0.470 \%$ terhadap Kinerja Organisasi pada Palang Merah Indonesia (PMI) Sigli Kabupaten Pidie. Hubungan antara variabel dependen dan independen yaitu masingmasing variabel Sistem Rekrutmen $\left(\mathrm{X}_{1}\right)$, Perilaku Organisasi $\left(\mathrm{X}_{2}\right)$ terhadap Kinerja Organisasi pada Palang Merah Indonesia (PMI) Sigli Kabupaten Pidie dengan indeks korelasi sebesar 0,929 $\%$ Ini berarti hubungan tersebut sangat kuat. Kemudian indeks determinasi masing-masing variabel Sistem Rekrutmen $\left(\mathrm{X}_{1}\right)$, Perilaku Organisasi $\left(\mathrm{X}_{2}\right)$ sebesar 0,864 \%, ini berarti keempat variabel berpengaruh secara signifikan terhadap Kinerja Organisasi pada Palang Merah Indonesia (PMI) Sigli Kabupaten Pidie, dan sebesar 13,6 \% yang dipengaruhi oleh variabel lain yang tidak diteliti dalam penelitian ini.
\end{abstract}

Kata Kunci: Sistem Rekrutmen, Perilaku Organisasi dan Kinerja Organisasi

\section{PENDAHULUAN}

Dalam mencapai tujuan yang telah ditetapkan sebelumnya, efektivitas menjadi salah satu masalah yang dihadapi oleh banyak perusahaan. Dalam hal ini peran pimpinan sangat penting untuk meningkatkan efektivitas kerja karyawan. Efektivitas kerja adalah penyelesaian pekerjaan tepat waktu yang ditentukan. Artinya pelaksanaan suatu pekerjaan dinilai baik atau sangat tidak baik tergantung pada penyelesaian tugas tersebut, bagaimana cara melaksanakannya dan berapa biaya yang dikeluarkan untuk itu.
Ruang lingkup rekrutmen adalah keseluruhan kegiatan dari upaya penarikan pegawai, seleksi dan penempatan yang intinya memperoleh pegawai yang berkualitas. Fungsi rekrutmen dalam perusahaan adalah merekrut staff atau pegawai agar perusahaan dapat menjalankan usahanya secara berkesinambungan. Kegagalan dalam melakukan perekrutan akan mempengaruhi kualitas kerja pegawai yang selanjutnya menjadi penghambat bagi proses pencapaian tujuan perusahaan. Proses perekrutan harus benar-benar dilakukan karena menyangkut proses jangka panjang 
dari tenaga kerja. Tidak hanya dalam sistem rekrutmen pegawai, keberhasilan suatu perusahaan dalam mencapai suatu tujuan sangat ditentukan oleh kemampuan pimpinan perusahaan dalam merencanakan tenaga kerja yang akan dipakai agar potensi pegawai dapat dimanfaatkan untuk memperoleh hasil yang maksimal. Kualitas kerja pegawai di dalam perusahaan banyak sekali dipengaruhi oleh berbagai faktor, beberapa diantaranya adalah sistem rekrutmen yang benar serta imbalan yang sesuai.

Rekrutmen Kader adalah ikhtiar aktif dan terencana untuk mendapatkan input calon kader yang berkualitas bagi proses Pembentukan Kader PMI Sigli dalam rangka mencapai tujuan PMI Sigli. Rekruetmen Kader meliputi masa Pra Perguruan Tinggi dan masa Perguruan Tinggi. Setiap pelamar selanjutnya akan melakukan proses seleksi sampai organisasi memutuskan layak atau tidak kader tersebut menempati pengurus PMI Sigli

Organisasi merupakan suatu perkumpulan orang yang memiliki tujuan bersama untuk memenuhi kebutuhan hidupnya. Perilaku organisasi merupakan pembelajaran tentang suatu sifat/karakteristik individu yang tercipta di lingkungan suatu organisasi. Karena manusia berbeda-beda karakteristik, maka perilaku organisasi berguna untuk mengetahui sifat-sifat individu dalam berkinerja suatu organisasi. Pembelajaran perilaku organisasi akan mengetahui tentang cara-cara mengatasi permasalahan yang ada di lingkungan organisasi. Dalam membantu dan menolong sesama manusia dapat mengikuti berbagai kegiatan positif seperti bakti sosial dan kelompok sosial lain yang bergerak dalam bidang kemanusiaan seperti menjadi relawan PMI dengan berbagai program yang bertujuan membantu sesama.

Kinerja organisasi pemerintah banyak menjadi sorotan akhir-akhir ini, terutama sejak timbulnya iklim yang lebih demokratis dalam pemerintahan. Rakyat mulai mempertanyakan akan nilai yang mereka peroleh atas pelayanan yang dilakukan oleh instansi pemerintah (organisasi publik). Selama ini pengukuran keberhasilan maupun kegagalan dari instansi pemerintah (organisasi publik) dalam menjalankan tugas pokok dan fungsinya sulit dilakukan secara objektif. Kinerja kerap diartikan secara sempit, yaitu sebagai prestasi kerja. Pencapaian kinerja suatu organisasi biasanya dilaksanakan dengan menggunakan manajeman pemerintahan yang baik.

Palang Merah Indonesia (PMI) adalah organisasi yang netral dan independent, yang melakukan kegiatannya demi kemanusiaan, kesukarelaan, kenetralan, kesamaan, kemandirian, kesatuan, dan kesemestaan. Palang Merah Indonesia tidak melibatkan diri/berpihak pada golongan politik, ras, suku ataupun agama tertentu. Dalam pelaksanaannya tidak melakukan pembedaan tetapi mengutamakan objek korban yang paling membutuhkan pertolongan segera untuk keselamatan jiwanya.

Pemantapan fungsi kekaderan PMI ditambah dengan kenyataan bahwa bangsa Indonesia sangat kekurangan tenaga kesehatan yang memiliki keseimbangan hidup yang terpadu antara pemenuhan tugas duniawi dan ukhrowi, iman dan ilmu, individu dan masyarakat, sehingga peranan kaum kesehatan yang semakin besar dimasa mendatang merupakan kebutuhan yang paling mendasar.

Berdasarkan hasil observasi, Palang Merah Indonesia (PMI) Sigli sekarang sudah berkurang tingkat kepeduliannya terhadap lingkungan sekitar, hal ini dikarenakan para pengurus yang kurang bersosialisasi dengan masyarakat, kondisi yang seperti ini sangat berpengaruh bagi pengrekrutan relawan dan kelangsungan intelektual.

Palang Merah Indonesia (PMI) Sigli memiliki tugas sosial kemanusian seperti menanggulangi bencana, pelayanan masyarat, pelatihan pertolongan pertama, serta membantu menyediakan donor darah. 
Dari dasar rasa kemanusiaan Palang Merah Indonesia (PMI) Sigli telah banyak menolong masyarakat yang membutuhkan. Seperti pada bagian penanggulangan bencana Palang Merah Indonesia (PMI) Sigli melakukan layanan masyarakat dengan melakukan pertolongan dan evakuasi, pelayanan kesehatan dan tim medis, pencarian, bpenyediaan dapur umum, pemberian paket sembako, rumah sakit lapangan, atau sumbangan pakaian.

\section{Rumusan Masalah}

Berdasarkan latar belakang masalah yang telah diuraikan di atas, maka masalah yang akan diteliti adalah:

1. Bagaimana pengaruh Sistem Rekrutmen dan terhadap Kinerja Organisasi Pada Palang Merah Indonesia (PMI) Sigli Kabupaten Pidie.?

2. Bagaimana pengaruh perilaku organisasi terhadap Kinerja Organisasi Pada Palang Merah Indonesia (PMI) Sigli Kabupaten Pidie.?

3. Variabel manakah yang lebih dominan berpengaruh terhadap Kinerja Organisasi Pada Palang Merah Indonesia (PMI) Sigli Kabupaten Pidie?

\section{METODE PENELITIAN}

\section{Lokasi}

Penelitian ini dilakukan pada Palang Merah Indonesia (PMI) Sigli Kabupaten Pidie, Alamat: Jln Iskandar Muda, AlunAlun Kota Sigli - Kabupaten Pidie. Aceh 24114.

\section{Objek Penelitian}

Objek Penelitian ini akan membahas tentang deskripsi organisasi, deskripsi responden, dan analisis indeks jawaban responden pervariabel independen dan dependen.

\section{Populasi dan Sampel Populasi}

Menurut Sugiyono (2010:117) populasi adalah wilayah generalisasi yang terdiri atas objek/subjek yang mempunyai kualitas dan karakteristik tertentu yang ditetapkan oleh peneliti untuk dipelajari dan kemudian ditarik kesimpulannya. Dalam penelitian ini populasi penelitian adalah pengurus yang ada pada Palang Merah Indonesia (PMI) Sigli Kabupaten Pidie dengan jumlah 32 orang.

\section{Sampel}

Menurut Arikunto (2008: 116) "Penentuan pengambilan Sample sebagai berikut :

Apabila kurang dari 100 lebih baik diambil semua hingga penelitiannya merupakan penelitian populasi. Jika jumlah subjeknya besar dapat diambil antara 10$15 \%$ atau $20-55 \%$ atau lebih tergantung sedikit banyaknya dari:

1. Kemampuan peneliti dilihat dari waktu, tenaga dan dana

2. Sempit luasnya wilayah pengamatan dari setiap subyek, karena hal ini menyangkut banyak sedikitnya dana.

3. Besar kecilnya resiko yang ditanggung oleh peneliti untuk peneliti yang resikonya besar, tentu saja jika samplenya besar hasilnya akan lebih baik.

Berdasarkan teori tersebut, maka penulis mengambil seluruh populasi sebagai sampel. Sehingga penelitian ini merupakan penelitian populasi yang berjumlah 32 orang.

\section{Teknik Pengumpulan Data \\ Data Primer}

Data primer adalah data yang dikumpulkan dan diolah sendiri oleh peneliti langsung dari responden berupa data opini dan kuesioner yang disebarkan. Kuesioner berisi daftar pertanyaan yang terstruktur dan materinya berhubungan dengan pengaruh sistem rekrutmen dan perilaku organisasi secara parsial dan simultan terhadap kinerja organisasi. 
Jurnal Sosial Humaniora Sigli (JSH)

p ISSN : 2615-3688

$e$ ISSN : 2716-0270

http://journal.unigha.ac.id/index.php/JSH

\section{Data Sekunder}

Data sekunder merupakan data yang diperoleh secara tidak langsung, yaitu data yang diperoleh dan diolah dari sumber Organisasi Palang Merah Indonesia (PMI) Sigli Kabupaten Pidie maupun dari internet, dan sebagainya.

\section{Skala Pengukuran}

Data hasil penelitian penelitian yang diperoleh melalui penyebaran kuisioner dalam bentuk kualitatif dikomposisikan terlebih dahulu agar menjadi data kuantitatif. Adapun nilai kuantitatif yang dikomposisikan dilakukan dengan menggunakan Skala Likert dan untuk satu pilihan dinilai dengan jarak interval 1. Nilai dari pilihan tersebut antara lain : 1,2,3,4,5. Masing-masing pilihan tersebut dapat dilihat dalam tabel dibawah ini:

Tabel 1

Skala Likert

\begin{tabular}{|c|c|}
\hline Keterangan (pilihan) & Skor \\
\hline $\begin{array}{l}\text { Sangat tidak setuju } \\
\text { (STS) } \\
\text { Tidak setuju (TS) } \\
\text { Kurang Setuju (KS) } \\
\text { Setuju (S) } \\
\text { Sangat setuju (SS) }\end{array}$ & $\begin{array}{l}2 \\
3 \\
4 \\
5\end{array}$ \\
\hline
\end{tabular}

\section{Operasional Variabel}

Definisi variabel adalah objek penelitian atau apa yang menjadi titik perhatian suatu penelitian. Dalam penelitian ini digunakan sejumlah variabel yang dibagi menjadi dua bagian yaitu : variabel independen (variabel bebas) dan variabel dependen (variabel terikat).

\section{PeralatanAnalisis Data}

Analisis statistik yang digunakan dalam penelitian ini adalah analisis regresi berganda dengan menggunakan program SPSS. Analisis regresi, untuk menghitung besarnya pengaruh secara kuantitatif dari suatu perubahan kejadian (variabel X) terhadap kejadian lainnya (variabel Y). Untuk melihat hubungan antara variabel yang dipergunakan rumus regresi berganda Umar (2008: 256).

$\mathrm{Y}=\mathrm{a}+\mathrm{b}_{1} \mathrm{X}_{1}+\mathrm{b}_{2} \mathrm{X}_{2}+\mathrm{e}$

Dimana :

$\begin{array}{ll}\mathrm{Y} & =\text { KinerjaOrganisasi } \\ \mathrm{a} & =\text { Konstanta } \\ \mathrm{b}_{1}, \mathrm{~b}_{2} & =\text { Koefisien regresi variabel } \\ \mathrm{X}_{1} & =\text { Sistem Rekrutmen } \\ \mathrm{X}_{2} & =\text { Perilaku Organisasi } \\ \mathrm{e} & =\text { error }\end{array}$

\section{Pengujian Validitas dan Reliabilitas Uji Validitas}

Uji validitas digunakan untuk menghitung korelasi antara masing-masing pernyataan dengan skor total dengan rumus korelasi product moment (Iqbal, 2008:15). Penghitungan uji validitas menggunakan bantuan SPSS 21.00 pada komputer.

Uji Validitas digunakan untuk mengukur sah atau tidaknya suatu kuesioner. Suatu kuesioner dikatakan valid jika pertanyaan pada kuesioner mampu untuk mengungkapkan sesuatu yang akan diukur oleh kuesioner tersebut. Uji validitas dihitung dengan membandingkan nilai $\mathrm{r}$ hitung (correlated item total correlations)dengan nilai $r$ tabel. Jika $r$ hitung > dari $\mathrm{r}$ tabel (pada taraf signifikan $10 \%$ ) maka pertanyaan tersebut diyantakan valid.

\section{Uji Reliabilitas}

Uji reliabilitas adalah suatu indeks yang menunjukkan sejauh mana hasil suatu pengukuran dapat dipercaya. Suatu kuesioner dinyatakan reliabel atau handal jika jawaban seseorang terhadap pertanyaan adalah konsisten atau stabil dari waktu ke waktu (Ghozali, 2011:56). Kehandalan yang menyangkut kekonsistenan jawaban jika diujikan berulang pada sampel yang berbeda.Penghitungan uji reliabilitas menggunakan bantuan SPSS 21.00 pada komputer. 
Dalam penelitian ini, uji reliabilitas dilakukan dengan melihat hasil perhitungan nilai cronbach alpha $(\alpha)$. Suatu variabel dikatakan reliabel jika memberikan nilai cronbach alpha $(\alpha)>0,6$ yaitu bila dilakukan penelitian ulang dengan waktu dan dimensi yang berbeda akan menghasilkan kesimpulan yang sama. Tetapi sebaliknya bila alpha $<$ 0,6 maka dianggap kurang handal.

\section{PengujianHipotesis}

H0: Variabel-variabel bebas (Sistem Rekrutmendan Perilaku Organisasi) tidak berpengaruh terhadap variabel terikat (Kinerja Organisasi) Pegawai Palang Merah Indonesia (PMI) Sigli Kabupaten Pidie.

Ha: Adanya pengaruh variabel-variabel bebas (Sistem Rekrutmen dan Perilaku Organisasi) terhadap variabel terikat (Kinerja Organisasi) Pegawai Palang Merah Indonesia (PMI) Sigli Kabupaten Pidie.

Untuk menguji Hipotesis dalam penelitian ini penulis menggunakan uji $\mathrm{F}$ dan uji $\mathrm{t}$ yaitu pada tingkat keyakinan (convindend interval 95\%) atau tingkat kesalahannya (alpha) a sebesar 0.05. Pada tingkat keyakinan (convided interval 95\%) atau tingkat kesalahan (alpha) a sebesar 0,05 maka apabila nilai signifikan < dari nilai alpha (5\%) maka $\mathrm{Ha}$ di terima dan sebaliknya apabila nilai signifikan > dari nilai alpha (5\%) maka Ha di tolak.

Untuk pengolahan data penelitian ini menggunakan SPSS (statistic package for social science) versi 21.0.

\section{PEMBAHASAN}

Untuk mengetahui pengaruh variable Sistem Rekrutmen, Perilaku Organisasi , Perilaku dan Pengalaman kerja terhadap Kinerja Organisasi pada Palang Merah Indonesia (PMI) Sigli Kabupaten Pidie, maka dilakukan analisis data melalui regresi linear berganda. Dimana hasilnya dapat dilihat pada Tabel 4.8 berikut:
Tabel 2

Pengaruh Masing-masing Variabel IndependenTerhadap Variabel Dependen

\begin{tabular}{|c|c|c|c|c|c|c|}
\hline $\begin{array}{c}\text { Nama } \\
\text { Variabe } \\
\text { l }\end{array}$ & B & $\begin{array}{c}\text { Sta } \\
\text { nda } \\
\mathbf{r} \\
\text { Err } \\
\text { or } \\
\end{array}$ & Beta & $\mathbf{t}_{\text {hitung }}$ & $\begin{array}{c}\mathbf{t} \\
\text { tabel }\end{array}$ & $\begin{array}{l}\text { Sig } \\
\text { n }\end{array}$ \\
\hline $\begin{array}{c}\text { Konsta } \\
\text { nta }\end{array}$ & 3.690 & 1.206 & & 3.059 & 1,697 & .001 \\
\hline $\begin{array}{l}\text { Sistem } \\
\text { Rekrut } \\
\text { men }\end{array}$ & 0.470 & $\begin{array}{c}0.09 \\
2\end{array}$ & $\begin{array}{c}0.52 \\
9\end{array}$ & 5.083 & 1,697 & .001 \\
\hline $\begin{array}{c}\text { Perilak } \\
\mathrm{u}\end{array}$ & 0.434 & $\begin{array}{c}0.09 \\
7\end{array}$ & $\begin{array}{c}0.46 \\
4\end{array}$ & 4.462 & 1,697 & .003 \\
\hline \multicolumn{5}{|c|}{$\begin{array}{l}\text { Koefisien Determinasi }\left(\mathrm{R}^{2}\right) \\
0,864\end{array}$} & \multicolumn{2}{|l|}{$=$} \\
\hline \multicolumn{5}{|c|}{$\begin{array}{l}\text { Adjusted R Squares } \\
0,855\end{array}$} & \multicolumn{2}{|l|}{$=$} \\
\hline \multicolumn{5}{|l|}{$\mathrm{F}_{\text {hitung }}$} & \multicolumn{2}{|c|}{$=$} \\
\hline
\end{tabular}

Sumber: Data Primer Penelitian Diolah (2019)

Dari output SPSS di atas dengan dipergunakan model regresi berganda, dapat difungsikan dalam bentuk persamaan sebagai berikut:

$$
\begin{gathered}
\mathrm{Y}=3.690+0.470 \mathrm{X}_{1}+0.434 \mathrm{X}_{2} \\
\text { Dari persamaan regresi linear }
\end{gathered}
$$
berganda di atas dapat dijelaskan sebagai berikut:

a. Nilai konstanta sebesar 3.690 artinya jika Sistem Rekrutmen $\left(\mathrm{X}_{1}\right), \quad$ Perilaku Organisasi $\left(\mathrm{X}_{2}\right)$, Perilaku $\left(\mathrm{X}_{3}\right)$ dan Pengalaman kerja $\left(\mathrm{X}_{4}\right)$, dianggap konstan, maka Kinerja Organisasi pada Palang Merah Indonesia (PMI) Sigli Kabupaten Pidie adalah sebesar 3.690.

b. Nilai koefisien regresi Sistem Rekrutmen sebesar 0.470 dapat diartikan bahwa setiap 1\% kenaikan Sistem Rekrutmen $\left(\mathrm{X}_{1}\right)$ maka akan meningkatkan Kinerja Organisasi pada Palang Merah Indonesia (PMI) Sigli Kabupaten Pidie sebesar 47 $\%$. Ini berarti terjadi Kinerja Organisasi pada Palang Merah Indonesia (PMI) Sigli Kabupaten Pidie. 
c. Nilai koefisien regresi Perilaku Organisasi sebesar 0.434 dapat diartikan bahwa setiap $1 \%$ kenaikan Perilaku Organisasi $\left(\mathrm{X}_{2}\right)$ maka akan meningkatkan Kinerja Organisasi pada Palang Merah Indonesia (PMI) Sigli Kabupaten Pidie sebesar $0.43,4 \%$. Ini berarti terjadi Kinerja Organisasi pada Palang Merah Indonesia (PMI) Sigli Kabupaten Pidie.

Berdasarkan hasil analisis di atas dapat disimpulkan bahwa dari keempat variabel yang diteliti, ternyata variabel Sistem Rekrutmen $\left(\mathrm{X}_{1}\right)$ mempunyai pengaruh yang paling dominan sebesar $0.470 \%$ terhadap Kinerja Organisasi pada Palang Merah Indonesia (PMI) Sigli Kabupaten Pidie.

Hubungan antara variabel dependen dan independen yaitu masing-masing variabel Sistem Rekrutmen $\left(\mathrm{X}_{1}\right)$, Perilaku Organisasi $\left(\mathrm{X}_{2}\right)$ terhadap Kinerja Organisasi pada Palang Merah Indonesia (PMI) Sigli Kabupaten Pidie dengan indeks korelasi sebesar 0,929 \% Ini berarti hubungan tersebut sangat kuat.

Kemudian indeks determinasi masingmasing variabel Sistem Rekrutmen $\left(\mathrm{X}_{1}\right)$, Perilaku Organisasi $\left(\mathrm{X}_{2}\right)$ sebesar 0,864\%, ini berarti keempat variabel berpengaruh secara signifikan terhadap Kinerja Organisasi pada Palang Merah Indonesia (PMI) Sigli Kabupaten Pidie, dan sebesar $13,6 \%$ yang dipengaruhi oleh variabel lain yang tidak diteliti dalam penelitian ini.

\section{Hasil Pengujian Hipotesis}

\section{Uji F}

Uji serempak atau uji F merupakan uji secara bersama-sama untuk menguji sigifikansi pengaruh variabel Sistem Rekrutmen $\left(\mathrm{X}_{1}\right)$, Perilaku Organisasi $\left(\mathrm{X}_{2}\right)$, terhadap variabel Kinerja Organisasi (Y). Uji $F$ dilakukan untuk melihat pengaruh variabel independen terhadap variabel dependen secara bersama-sama (secara simultan). Pembuktiannya dapat dijelaskan sebagai berikut:
Tabel 3

Hasil Analisis Uji F

\begin{tabular}{|l|l|r|r|r|r|r|r|}
\hline \multicolumn{2}{|c|}{ Model } & $\begin{array}{c}\text { Sum of } \\
\text { Squares }\end{array}$ & Df & $\begin{array}{c}\text { Mean } \\
\text { Square }\end{array}$ & F & F $_{\text {tabel }}$ & Sig. \\
\hline \multirow{2}{*}{1} & Regression & 56.129 & 2 & 28.065 & 92.072 & 2,46 & 0,000 \\
\cline { 2 - 8 } & Residual & 8.840 & 29 & .305 & & & \\
\cline { 2 - 8 } & Total & 64.969 & 31 & & & & \\
\hline
\end{tabular}

Sumber: Data Primer Penelitian Diolah (2019)

Hasil pengujian secara simultan di peroleh $F_{\text {hitung }} 92.072>F_{\text {tabel }} 2,46$. Dengan demikian hasil perhitungan ini dapat diambil suatu keputusan bahwa menerima hipotesis alternatif (Ha) dan menolak hipotesis nol (Ho), artinya bahwa variabel Sistem Rekrutmen $\left(\mathrm{X}_{1}\right)$ dan Perilaku Organisasi $\left(\mathrm{X}_{2}\right)$ secara bersama-sama berpengaruh secara signifikan terhadap Kinerja Organisasi pada Palang Merah Indonesia (PMI) Sigli Kabupaten Pidie.

\section{Uji t}

Pengujian ini untuk melihat sejauh mana pengaruh secara terpisah dari masingmasing variabel Sistem Rekrutmen $\left(\mathrm{X}_{1}\right)$ dan Perilaku Organisasi $\left(\mathrm{X}_{2}\right)$ terhadap variabel terikat $(\mathrm{Y})$ berdasarkan hasil regresi yang ada, uji t dilakukan dengan membandingkan nilai $\mathrm{t}$ hitung dengan $\mathrm{t}$ tabel dengan tingkat kesalahan 5\%. Uji t dilakukan untuk melihat signifikan dari pengaruh variabel independen secara individu terhadap variabel dependen (secara parsial). Pembuktian hipotesis secara parsial dapat dijelaskan seperti tabel 4.12 di bawah ini, maka dapat disajikan sebagai berikut:

Tabel 4

\section{Hasil Analisis Uji t}

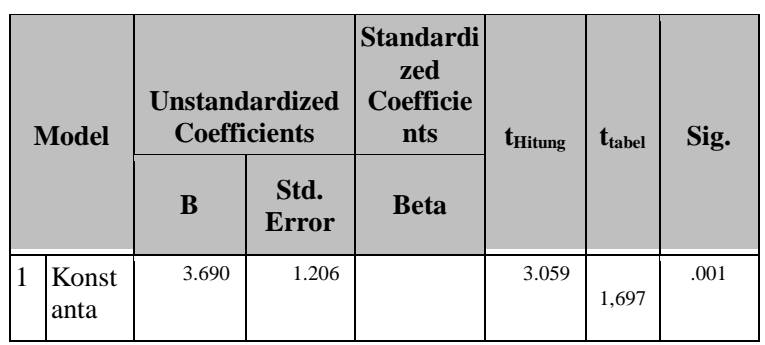


Jurnal Sosial Humaniora Sigli (JSH)

p ISSN : 2615-3688

$e$ ISSN : 2716-0270

http://journal.unigha.ac.id/index.php/JSH

\begin{tabular}{|l|l|l|l|l|l|l|}
\hline $\begin{array}{l}\text { Sistem } \\
\text { Rekrut } \\
\text { men }\end{array}$ & 0.470 & 0.092 & 0.529 & 5.083 & 1,697 & .001 \\
\hline $\begin{array}{l}\text { Perila } \\
\text { ku } \\
\begin{array}{l}\text { Organi } \\
\text { sasi }\end{array}\end{array}$ & 0.434 & 0.097 & 0.464 & 4.462 & & .003 \\
\hline
\end{tabular}

Sumber: Data Primer Penelitian Diolah (2019)

a. Variabel Sistem Rekrutmen $\left(\mathrm{X}_{1}\right)$ diperoleh $t_{\text {hitung }} 5.083>t_{\text {tabel }}$ 1,697 dan nilai signifikan $0.000<0.05$, sehingga Hipotesis Nol (Ho) diterima dan Hipotesis Alternatif (Ha) ditolak. Dari hasil uji $t$ ini dapat disimpulkan bahwa variabel Sistem Rekrutmen $\left(\mathrm{X}_{1}\right)$ berpengaruh secara signifikan terhadap Kinerja Organisasi pada Palang Merah Indonesia (PMI) Sigli Kabupaten Pidie.

b. Variabel Perilaku Organisasi $\left(\mathrm{X}_{2}\right)$ diperoleh $\mathrm{t}_{\text {hitung }} 4.462>\mathrm{t}_{\text {tabel }} 1,697$ dan nilai signifikan $0,000>0.05$, sehingga Hipotesis Nol (Ho) ditolak dan Hipotesis Alternatif (Ha) ditoerima. Dari hasil uji t ini dapat disimpulkan bahwa variabel Perilaku Organisasi $\left(\mathrm{X}_{2}\right)$ berpengaruh secara signifikan terhadap Kinerja Organisasi pada Palang Merah Indonesia (PMI) Sigli Kabupaten Pidie.

\section{KESIMPULAN DAN SARAN Kesimpulan}

Kesimpulan dari hasil penelitian tentang "Pengaruh Sistem Rekrutmen dan Perilaku Organisasi Terhadap Kinerja Organisasi pada Palang Merah Indonesia (PMI) Sigli Kabupaten Pidie" adalah sebagai berikut:

a. Berdasarkan hasil analisis di atas dapat disimpulkan bahwa dari keempat variabel yang diteliti, ternyata variabel Sistem Rekrutmen $\left(\mathrm{X}_{1}\right)$ mempunyai pengaruh yang paling dominan sebesar $0.470 \%$ terhadap Kinerja Organisasi pada Palang Merah Indonesia (PMI) Sigli Kabupaten Pidie.

b. Hubungan antara variabel dependen dan independen yaitu masing-masing variabel Sistem Rekrutmen $\left(\mathrm{X}_{1}\right)$, Perilaku Organisasi $\left(\mathrm{X}_{2}\right)$ terhadap
Kinerja Organisasi pada Palang Merah Indonesia (PMI) Sigli Kabupaten Pidie dengan indeks korelasi sebesar 0,929\% Ini berarti hubungan tersebut sangat kuat.

c. Kemudian indeks determinasi masingmasing variabel Sistem Rekrutmen $\left(\mathrm{X}_{1}\right)$, Perilaku Organisasi $\left(\mathrm{X}_{2}\right)$ sebesar $0,864 \%$, ini berarti keempat variabel berpengaruh secara signifikan terhadap Kinerja Organisasi pada Palang Merah Indonesia (PMI) Sigli Kabupaten Pidie, dan sebesar 13,6 \% yang dipengaruhi oleh variabel lain yang tidak diteliti dalam penelitian ini.

d. Hasil pengujian secara simultan di peroleh $F_{\text {hitung }} 92.072>F_{\text {tabel }} 2,46$. Dengan demikian hasil perhitungan ini dapat diambil suatu keputusan bahwa menerima hipotesis alternatif $(\mathrm{Ha})$ dan menolak hipotesis nol (Ho), artinya bahwa variabel Sistem Rekrutmen $\left(\mathrm{X}_{1}\right)$ dan Perilaku Organisasi $\left(\mathrm{X}_{2}\right)$ secara bersama-sama berpengaruh secara signifikan terhadap Kinerja Organisasi pada Palang Merah Indonesia (PMI) Sigli Kabupaten Pidie.

e. Variabel Sistem Rekrutmen $\left(\mathrm{X}_{1}\right)$ diperoleh $t_{\text {hitung }} 5.083>\mathrm{t}_{\text {tabel }} 1,697$ dan nilai signifikan $0.000<0.05$, sehingga Hipotesis Nol (Ho) diterima dan Hipotesis Alternatif (Ha) ditolak. Dari hasil uji $\mathrm{t}$ ini dapat disimpulkan bahwa variabel Sistem Rekrutmen $\left(\mathrm{X}_{1}\right)$ berpengaruh secara signifikan terhadap Kinerja Organisasi pada Palang Merah Indonesia (PMI) Sigli Kabupaten Pidie.

f. Variabel Perilaku Organisasi $\left(\mathrm{X}_{2}\right)$ diperoleh $\mathrm{t}_{\text {hitung }} 4.462>\mathrm{t}_{\text {tabel }} 1,697$ dan nilai signifikan $0,000>0.05$, sehingga Hipotesis Nol (Ho) ditolak dan Hipotesis Alternatif (Ha) ditoerima. Dari hasil uji t ini dapat disimpulkan bahwa variabel Perilaku Organisasi $\left(\mathrm{X}_{2}\right)$ berpengaruh secara signifikan terhadap Kinerja Organisasi pada Palang Merah Indonesia (PMI) Sigli Kabupaten Pidie. 
Jurnal Sosial Humaniora Sigli (JSH)

p ISSN : 2615-3688

$e$ ISSN : 2716-0270

http://journal.unigha.ac.id/index.php/JSH

\section{Saran-Saran}

Untuk kegunaan penelitian dan kelangsungan usaha maka dapat saya berikan sedikit saran. Adapun saran yang dapat saya berikan adalah sebagai berikut:

a. Untuk meningkatkan Kinerja Organisasi pada Palang Merah Indonesia (PMI) Sigli Kabupaten Pidie, sebaikanya pengurus Palang Merah Indonesia (PMI) Sigli Kabupaten Pidie harus lebih tau mengenai kendala-kendala tentang pelayanan dalam meningkatkan kinerja organisasinya.

b. Untuk meningkatkan Kinerja Organisasi pada Palang Merah Indonesia (PMI) Sigli Kabupaten Pidie, Pihak PMI dan Pemerintah Kabupaten Pidie harus memperhatikan aspek-asepek penting yang di butuhkan Palang Merah Indonesia (PMI) Sigli Kabupaten Pidie supaya organisasi dapat berjalan sesuai dengan harapan.

\section{DAFTAR PUSTAKA}

AA. Anwar Prabu Mangkunegara, (2009). Manajemen Sumber Daya Manusia Perusahaan. Bandung : Rosda.

Achmad S.Ruky, 2011, Sistem Manajemen Kinerja, Bumi Aksara. Jakarta.

Arikunto, Suharsimi. 2012. Prosedur Penelitian. Jakarta: Rineka Cipta

Atmosudirdjo, Prayudi, 2009, Hukum Administrasi Negara, cetakan 10, Ghalia Indonesia, Jakarta.

Baban Sobandi dkk. 2009. Desentralisasi dan Tuntutan Penataan Kelembagaan Daerah. Bandung.

Bastian, Indra. 2010. Akuntansi Sektor Publik Suatu Pengantar Edisi Ketiga. Penerbit Erlangga :Jakarta

Dessler, Gary, 2011. Manajemen sumber daya manusia. Penerbit Indeks,
Jakarta

Ghozali, Imam. 2011. "Aplikasi Analisis Multivariate Dengan Program SPSS". Semarang: Badan Penerbit Universitas Diponegoro.

Gregor Polancik. (2009). Empirical Research Method Poster. Jakarta

Nurmansyah, 2011. Manajemen Sumber Daya Manusia Suatu Pengantar. Unilak Press, Pekanbaru

Rivai, Veithzal, dan Ella Jauvani Sagala, 2009. Manajemen Sumber Daya Manusia Untuk Perusahaan. PT. Rajagrafindo persada, Jakarta.

Simamora, Henry, 2015. Manajemen Sumber Daya Manusia. Penerbit STIE YKPN, Yogyakarta.

Stringer, Robert. 2012. Leadership and Organizational Climate : The Cloud Chamber Effect. Upper Saddle River, NJ : Prentice Hall

Sudjana, Nana. 2012. Penilaian Hasil dan Proses Penelitian. Bandung: Rosda Karya.

Sugiyono. 2010. Metode Penelitian Pendidikan Pendekatan Kuantitatif, kualitatif, dan $R \& D$. Bandung: Alfabeta

Surjadi. 2009. Pengembangan Kinerja Pelayanan Publik. Bandung. PT Rafika Aditama.

Sutrisno, Edy. 2010. Manajemen Sumber Daya Manusia. Jakarta: Kencana.

Tagiuri, R. \& Litwin G. 2009. Organizational Climate: Expectations of a Concept. Boston: Harvard University Press

Thoha, Miftah. 2010. Manajemen 
Jurnal Sosial Humaniora Sigli (JSH)

p ISSN : 2615-3688

$e$ ISSN : 2716-0270

http://journal.unigha.ac.id/index.php/JSH

Kepegawaian Sipil Di Indonesia. Jakarta: Kencana.

Umar, Husein, 2008. Metode Penelitian Untuk Skripsi dan Tesis Bisnis. PT Rajawali Press, Jakarta.

Empat.

2011. Evaluasi Teori Model Standar Aplikasi dan Profesi, Contoh Aplikasi Evaluasi Program: Pengembangan Sumber Daya Manusia, Program Nasional

Wibowo, 2011. Manajemen kinerja. Penerbit Rajagrafindo Persada, Jakarta pemberdayaan Masyarakat (PNPM) Mandiri Pedesaan, Kurikulum, Perpustakaan, dan Buku Tes. Jakarta: Raja Grafindo Persada.

Wirawan. 2009. Evaluasi Kinerja Sumber Daya Manusia : Teori Aplikasi dan Penelitian. Jakarta: Salemba 